\title{
Estimation of Metabolic Status in High Yielding Dairy Cows During Transition Period and Full Lactation
}

\author{
Radojica Djokovic ${ }^{1}$, Marko Cincovic ${ }^{2}$, Zoran Ilic ${ }^{3}$, Vladimir Kurcubic', \\ Biljana Andjelic ${ }^{4}$, Milos Petrovic ${ }^{1}$, Nebojsa Lalic $^{3} \&$ Boban Jasovic $^{3}$
}

\begin{abstract}
Background: Major changes in the metabolic functions in high-yielding dairy cows occur during the transitional period and during lactation. Parturition and lactogenesis are accompanied by many physiological changes that facilitate the maintenance of homeostasis Consequently, physiological situations leading to a negative energy balance are coupled to an increased uncontrolled rate of body fat mobilisation and the increased fatty acids accumulation in hepatocytes and blood ketone bodies, resulting in disturbances of the morphological and physiological liver integrity. The objective of the present study was to estimate metabolic status in late pregnant, early lactation and full lactation Holstein dairy cows on the basis changes of blood concentrations of selected biochemical markers.

Materials, Methods \& Results: The experiment included 36 Holstein cows. Three groups of clinically healthy cows were chosen from the herd. Group 1 consisted of late pregnant cows $(n=12)$ from 30 to 1 day $(20 \pm 15)$ to partus; Group 2 comprised early lactation cows $(\mathrm{n}=12)$ in the first month of lactation $(15 \pm 12$ days), and Group 3 included full lactation cows $(\mathrm{n}=12)$ between 60 to 90 days of lactation $(81 \pm 30$ days). Blood samples were collected from all cows, by punction of the jugular vein. Biochemical testing for markers in the blood serum showed significantly lower values $(P<0.05)$ of glucose, TG, Tchol. and urea in early cows than in full lactation and late-pregnant cows. The blood concentration of NEFA and BHB was significantly increased $(P<0.05)$ in the group of cows in early lactation compared to the other groups of cows. The mean tBIL. concentration and the serum AST, GGT and ALT activities were markedly increased $(P<0.01)$ in the lactation cows compared to the late pregnant cows. Furthermore, the intensity of lipomobilisation (NEFA or BHB concentrations) correlated positively $(P<0.05)$ with the markers of cell damage or liver function impairment (tBIL., serum AST, ALT and GGT activities), but negatively $(P<0.05)$ with the circulating concentrations of compounds synthesised in liver (glucose, TG and urea).

Discussion: In dairy cows, it was observed that up to $50 \%$ of females exhibited some lipid accumulation in liver in the first 3 weeks after calving and that fatty liver occurs primarily in this period. Liver can be categorized into mild, moderate and severe fatty liver as dependent on the degree of pathology and a mild fatty infiltration of liver in dairy cows during lactation is considered to be almost physiological. The blood BHB and NEFA concentrations are markers of lipomobilisation and positively associated with the ketosis and liver steatosis intensity. The simultaneous and parallel variations observed between the extent of the fat infiltration in liver and the serum BHB and NEFA concentrations in puerperal cows clearly indicated that the intense lipomobilisation in the post-partum period has induced lipid overloading and ketogenesis in the liver. On the other hand, it was observed significant decreases in the serum biochemical markers, at least partially synthesised in the liver, such as glucose, TG, Tchol., urea, albumin and TP during the postpartum period. However, the liver steatosis has induced some cellular lesions as evidenced by significant increases in the serum tBIL. concentrations and in the AST, ALT, GGT and LDH enzyme activities in puerperal cows. All these biochemical metabolites may be used as important biochemical markers in the determination of the metabolic status in high-yielding dairy cows during the transition period and during lactation.
\end{abstract}

Keywords: dairy cows, transition period, full lactation, blood metabolites, blood enzymes.

DOI: $10.22456 / 1679-9216.92100$

${ }^{1}$ Department of Animal Science, Faculty of Agronomy - Cacak, University of Kragujevac, Cacak, Serbia. ${ }^{2}$ Department of Veterinary Medicine, Faculty of Agriculture, Novi Sad, University of Novi Sad, Novi Sad, Serbia. ${ }^{3}$ Department of Animal Science, Faculty of Agronomy, University of Pristina, Lesak, Serbia. ${ }^{4}$ Department of Animal Science, Faculty of Agriculture - Krusevac, University of Nis, Serbia. CORRESPODENCE: R. Djokovic [radojicadjokovic@gmail.com - Fax: +381 (0)32303400]. Department of Animal Science, Faculty of Agronomy - Cacak, University of Kragujevac. Cara Dusana n. 34. 32000 Cacak, Serbia. 
R. Djokovic, M. Cincovic, Z. Ilic, et al. 2019. Estimation of Metabolic Status in High Yielding Dairy Cows During Transition

\section{INTRODUCTION}

Production diseases i.e. diseases associated with improper nutrition or management are common in dairy cows during lactation period $[2,4]$. Dairy cows have negative energy balance (NEB) during the early lactation due to energy expenditure associated with milk production and limited feed intake, resulting in NEB, a high mobilization of lipids from body fat reserve, liver lipidosis, ketogenesis and hypoglycaemia $[5,6,9,10,16,21]$. The main blood markers of lipomobilization in dairy cows are BHB, the most important ketone body, and NEFA $[3,9,15]$. NEFA are accumulated as TG in the liver, primarily because of a decrease in the very low density lipoproteins (VLDL) synthesis by liver cells [11,19]. However, under lipidosis conditions, endogenous liver synthesis decreased, resulting in reduced levels of blood glucose, TP, albumin, globulin, tChol., TG and urea $[1,5,6,19]$. Furthermore, the excretory capacity of hepatocytes is decreased and, accordingly, the blood concentrations of some metabolites such as tBIL, ammonia and bile acids are generally increased [1,5,19,22]. The fatty liver infiltration and hepatocyte degeneration involve cell membrane damage and hepatocyte destruction coupled with the release of cytoplasm enzymes and significantly increase in the circulating activities $[14,17,20]$.

The objective of the present study was to estimate metabolic status in transitional and full lactations dairy cows on the basis changes of blood concentrations of selected biochemical markers.

\section{MATERIALS AND METHODS}

\section{Animals}

A total of 36 dairy cows were selected from the same Holstein herd containing 445 cows (FARM: Sarulja, Kragujevac, Central Serbia). Three groups of clinically healthy cows were chosen from the herd. Group 1 consisted of late pregnant cows $(n=12)$ from 30 to 1 day (20 \pm 15 ) to partus; Group 2 comprised early lactation cows $(\mathrm{n}=12)$ in the first month of lactation ( $15 \pm 12$ days $)$, and Group 3 included full lactation cows $(n=12)$ between 60 to 90 days of lactation ( $81 \pm 30$ days). The cows were high-yielding with a preceding lactation of about $8,500 \mathrm{~L}$ (late pregnant cows: $8,325 \pm 795 \mathrm{~L}$, early lactation cows 8,458 $\pm 920 \mathrm{~L}$, and mid-lactation cows: 8,677 $\pm 1055 \mathrm{~L}$ ). The experimental cows were housed in open-stall barns. Diet and housing facilities were adapted to research purposes, with diet suited to the energy requirement of late-pregnant, early lactation and mid-lactation cows. Diet for late-pregnant cows included $7 \mathrm{~kg}$ grass hay, 5 $\mathrm{kg}$ corn silage (30\% Dry Matter, DM), $4 \mathrm{~kg}$ sweet corn silage, $6 \mathrm{~kg}$ beet noodle silage, $5 \mathrm{~kg}$ straw, $1 \mathrm{~kg}$ concentrate (18\% crude protein, CP). Diet for early lactation cows consisted of $4 \mathrm{~kg}$ grass hay, $10 \mathrm{~kg}$ corn silage (30\% Dry Matter, DM), $20 \mathrm{~kg}$ sweet corn silage, $12 \mathrm{~kg}$ beet noodle silage, $4 \mathrm{~kg}$ concentrate ( $18 \%$ crude protein, $\mathrm{CP}$ ) and 1 $\mathrm{kg}$ molasses. Diet for full lactation cows contained 4.5 $\mathrm{kg}$ alfalfa hay, $19 \mathrm{~kg}$ corn silage (30\% Dry Matter, DM), $16 \mathrm{~kg}$ beet noodle silage, $9 \mathrm{~kg}$ concentrate $(18 \%$ crude protein, $\mathrm{CP}$ ) and $1.2 \mathrm{~kg}$ soybean expeller.

The chemical composition of total mixed rations offered to late pregnant, early lactation and full lactation dairy cows is given in Table 1.

Table 1. Chemical composition of total mixed rations offered to late pregnant, early lactation and full lactation dairy cows.

\begin{tabular}{cccc}
\hline & Late pregnancy & Early lactation & Full lactation \\
\hline Dry Matter (DM) (kg) & 12.85 & 15.60 & 19.58 \\
Net Energy of Lactation (NEL) (MJ) & 60.94 & 95.52 & 128.65 \\
Crude Protein (CP) (\% of DM) & 8.25 & 33.91 & 26.33 \\
Rumen undegradable protein (RUP) $(\%$ of CP) & 28.86 & 3.47 & 4.68 \\
Fiber (\% of DM) & 2.41 & 22.17 & 18.85 \\
\hline
\end{tabular}




\section{Blood sampling and laboratory procedures}

The blood samples were collected after morning milking and feeding, by puncture of the jugular vein into sterile disposable test tubes without anticoagulant. After clotting for $3 \mathrm{~h}$ at $4^{\circ} \mathrm{C}$ and centrifugation $(1500 \mathrm{x} g, 10 \mathrm{~min}$, $4^{\circ} \mathrm{C}$ ), sera were carefully harvested and stored at $-20^{\circ} \mathrm{C}$ until analysis. Blood samples collected on fluoride were immediately centrifuged according to the same modalities and plasmas were assessed for glucose concentrations. The beta-hydroxybutyrate (BHB), non-esterified fatty acids (NEFA), triglyceride (TG), total cholesterol (tChol), glucose, total protein (TP), albumin, urea, total bilirubin (tBIL) and serum aspartate transaminase (AST) gammaglutamyl transferase (GGT) and alanine aminotransferase (ALT) were measured at the Biochemical Laboratory ${ }^{1}$, by photometric methods using a Cobas Mira automatic analyzer and corresponding commercial kits ${ }^{2,3}$.

\section{Statistical analysis}

The statistical analysis of the obtained data was carried out by ANOVA-procedure. The analysis of variance were used to evaluate the probability of the significance of the statistical differences between mean biochemical markers values in each group and the Pearson test was performed for evidencing significant correlations. Differences were considered as significant when $P$ values were below 0.05 or 0.01 . For this purpose was used statistic software (Statgraphic Centurion, Statpoint Technologies Inc.Warrenton, Va, Virginia, USA).

\section{RESULTS}

Blood biochemical markers in the transition and full lactation dairy cows were compared in this study (Table 2).

Table 2. Blood metabolites in late pregnant (Group 1), early lactation (Group 2) and full lactation (Group 3) dairy cows ( $\mathrm{n}=12$ per group). Results are expressed as mean \pm standard deviation (SD).

\begin{tabular}{cccc}
\hline Variable & Group 1 & Group 2 & Group 3 \\
\hline Glucose $(\mathrm{mmol} / \mathrm{L})$ & $3.17 \pm 0.32^{\mathrm{a}}$ & $2.63 \pm 0.53^{\mathrm{b}}$ & $3.00 \pm 0.28^{\mathrm{a}}$ \\
BHB $(\mathrm{mmol} / \mathrm{L})$ & $1.10 \pm 0.32^{\mathrm{a}}$ & $1.48 \pm 0.25^{\mathrm{b}}$ & $0.87 \pm 0.20^{\mathrm{a}}$ \\
NEFA $(\mathrm{mmol} / \mathrm{L})$ & $0.16 \pm 0.07^{\mathrm{a}}$ & $0.36 \pm 0.20^{\mathrm{b}}$ & $0.12 \pm 0.05^{\mathrm{a}}$ \\
TG(mmol/L) & $0.13 \pm 0.05^{\mathrm{A}}$ & $0.03 \pm 0.03^{\mathrm{B}}$ & $0.04 \pm 0.04^{\mathrm{B}}$ \\
tChol. $(\mathrm{mmol} / \mathrm{L})$ & $3.63 \pm 1.83^{\mathrm{A}}$ & $2.93 \pm 0.59^{\mathrm{A}}$ & $5.93 \pm 1.17^{\mathrm{B}}$ \\
TP $(\mathrm{g} / \mathrm{L})$ & $73.10 \pm 6.23^{\mathrm{a}}$ & $68.36 \pm 7.62^{\mathrm{a}}$ & $72.36 \pm 5.5^{\mathrm{a}}$ \\
Albumin $(\mathrm{g} / \mathrm{L})$ & $35.09 \pm 2.25^{\mathrm{a}}$ & $32.64 \pm 4.46^{\mathrm{a}}$ & $34.63 \pm 2.61^{\mathrm{a}}$ \\
Urea $(\mathrm{mmol} / \mathrm{L})$ & $4.81 \pm 1.34^{\mathrm{a}}$ & $3.67 \pm 0.71^{\mathrm{b}}$ & $4.70 \pm 1.09^{\mathrm{a}}$ \\
tBIL. $(\mu \mathrm{mol} / \mathrm{L})$ & $3,14 \pm 0.77^{\mathrm{A}}$ & $7.27 \pm 5.24^{\mathrm{B}}$ & $3.20 \pm 1.70^{\mathrm{a}}$ \\
AST $(\mathrm{IU} / \mathrm{L})$ & $59.72 \pm 10.95^{\mathrm{A}}$ & $90.81 \pm 21.98^{\mathrm{B}}$ & $84.18 \pm 16.19^{\mathrm{B}}$ \\
GGT $(\mathrm{IU} / \mathrm{L})$ & $15.82 \pm 2.4^{\mathrm{A}}$ & $23.45 \pm 7.8^{\mathrm{B}}$ & $26.54 \pm 6.21^{\mathrm{B}}$ \\
ALT $(\mathrm{IU} / \mathrm{L})$ & $28.54 \pm .96^{\mathrm{A}}$ & $28.00 \pm 8.46^{\mathrm{A}}$ & $36.45 \pm 9.62^{\mathrm{B}}$ \\
\hline
\end{tabular}

Mean values within a row with no common superscript differ significantly; values followed by small letters differ significantly $(P<0.05)$; values marked with capital letters differ highly significantly $(P<0.01)$.

The serum concentrations of NEFA and BHB were significantly higher during early lactation than during late pregnancy and full lactation $(P<0.05)$ whereas the mean TG and Tchol. concentration was significantly lowered $(P<0.01)$. In addition, the glucose and urea concentrations were markedly depressed in the early lactation cows $(P<0.05)$ compared to late pregnancy and full lactation and the proteinemia and albuminemia was not significantly altered although this parameter was slightly decreased in the puerperal cows. By contrast, the tBIL. concentrations and the serum enzyme AST, GGT and ALT activities were markedly increased $(P<0.01)$ in the lactation cows compared to the pregnant females. Correlation between biochemical markers calculated for all cows were estimated in this study (Table 3). 
R. Djokovic, M. Cincovic, Z. Ilic, et al. 2019. Estimation of Metabolic Status in High Yielding Dairy Cows During Transition

Table 3. Correlation coefficients for biochemical markers in blood calculated for all cows in the present study.

\begin{tabular}{cccccccccccc}
\hline & BHB & NEFA & TG & tChol. & TP & albumin & urea & tBIL & AST & GGT & ALT \\
\hline glucose & -0.23 & $\mathbf{- 0 . 4 0}$ & 0.22 & 0.30 & -0.14 & 0.20 & 0.26 & $\mathbf{- 0 , 4 1}$ & $\mathbf{- 0 . 3 8}$ & 0.19 & $\mathbf{- 0 . 3 7}$ \\
BHB & & $\mathbf{0 . 4 7}$ & $\mathbf{- 0 . 4 2}$ & -0.15 & 0.25 & 0.14 & $\mathbf{- 0 . 3 4}$ & $\mathbf{0 . 3 8}$ & $\mathbf{0 . 4 5}$ & $\mathbf{0 . 5 3}$ & 0.26 \\
NEFA & & & $\mathbf{- 0 . 3 5}$ & -0.13 & 0.15 & 0.12 & -0.18 & $\mathbf{0 . 5 6}$ & $\mathbf{0 . 5 2}$ & $\mathbf{0 . 4 6}$ & $\mathbf{0 . 3 5}$ \\
TG & & & $\mathbf{0 . 5 3}$ & $\mathbf{0 . 3 8}$ & 0.15 & -0.15 & 0.05 & -0.26 & $\mathbf{- 0 . 5 4}$ & -0.18 \\
tChol. & & & & 0.03 & 0.02 & 0.09 & $\mathbf{- 0 . 4 8}$ & 0.11 & $\mathbf{- 0 . 7 7}$ & $\mathbf{- 0 . 7 0}$ \\
TP & & & & & 0.17 & 0.10 & -0.03 & -0.18 & 0.21 & -0.01 \\
albumin & & & & & & $\mathbf{0 . 4 0}$ & -0.02 & 0.14 & -0.02 & 0.21 \\
urea & & & & & & & $-\mathbf{0 . 4 6}$ & $\mathbf{- 0 . 7 8}$ & -0.14 & 0.19 \\
tBIL & & & & & & & & & $\mathbf{0 . 5 0}$ & $\mathbf{0 . 3 4}$ & $\mathbf{0 . 3 6}$ \\
AST & & & & & & & & & & 0.24 & 0.19 \\
GGT & & & & & & & & & & & \\
\hline
\end{tabular}

Significant correlations $(P<0.05)$ are presented in bold.

In this study, the serum NEFA and BHB concentrations were positively coupled together $(P<0.05)$ and with damage markers (tBIL., AST and GGT activities, $P<0.05)$, but negatively and significantly $(P<$ 0.05 ) with the circulating concentrations of compounds synthesised in liver (TG and urea). It was also found positive and significant $(P<0.05)$ associations between analytes produced in liver (urea concentrations with albumin, and TG with Tchol. and TP) and among AST, ALT, GGT activities with tBIL. $(P<0.05)$ and negative associations (between urea with tBIL. and AST and between TChol. with tBIL, ALT and GGT, $P<0.05$ ).

\section{DISCUSSION}

The blood glucose concentrations in the late pregnant and lactating groups of cows were within the physiological values, from 2.5 to $4.2 \mathrm{mmol} / \mathrm{L}$ [18]. But, blood glucose levels were statistically significantly lower in the early lactation cows, which suggested an increased glucose uptake by the mammary gland and decreased gluconeogenesis in the liver $[4,7,13,21]$.

The blood concentration of NEFA as the best indicator of negative energy balance and the lipomobilisation during the transition period $[3,6,9]$ was significantly increased in the group of cows in early lactation compared to the groups of late pregnant and full lactation cows. The serum BHB concentration is another indicator of energy metabolism in the early lactating cows showed also significantly higher concentrations than the pregnant and full lactation cows, suggesting a intensive mobilisation of fat stores. Subclinical ketosis may be diagnosed when serum BHB concentrations are above $1.2 \mathrm{mmol} / \mathrm{L}$, and clinical ketosis with blood BHB level above $2.6 \mathrm{mmol} / \mathrm{L}$ $[2,8,15]$. The early lactation cows had the indicative values of the BHB $(1.48 \pm 0.25 \mathrm{mmol} / \mathrm{L})$ but did not show any clinical signs, which means that they had a typical subclinical condition. Markers of lipomobilisation (NEFA or BHB concentrations) were found positively correlated together in the current study. The serum BHB and NEFA concentrations in puerperal cows clearly indicated that the intense lipomobilisation in the post-partum period has induced ketogenesis and lipid infiltration in the liver $[3,6,8,10,12,15]$.

On the other hand, significant decreases in serum TG and tChol. concentrations were observed in groups of lactating cows compared to late-pregnant cows and other biochemical metabolites synthesized in the liver, such as glucose, albumin, urea and TP were also decreased during the puerperal period. These results suggested an increased accumulation of TG and tChol. in hepatocytes in puerperal cows, which was probably associated with decreased liver synthesis of VLDLs, and can confirm the reduction of liver synthesis induced by the development of fatty infiltration in the liver $[1,11,12,19]$. It was also confirmed a positive associations between in liver sintetised indicators: urea with albumin and TG with tChol and TP in this study.

By contrast, liver damage induces an increase in the serum tBIL and the haemic compound is con- 
sidered as a sensitive marker for liver injury [1,5,22]. In this study, the mean tBIL. concentration was markedly increased in the puerperal cows compared to the late pregnant and full lactation dairy cows. As tBIL. concentrations, high serum activities of some enzymes highly expressed in liver in dairy cows such as AST, ALT and GGT are observed in liver injury and highly contribute to evaluate the degree of tissue damage $[5,14,17,20]$.

In the present study, the serum AST, GGT and ALT activities were significantly higher in early and full lactation cows than in late pregnant cows, suggested that the process of lipomobilization was sufficient to cause mild fat infiltration of liver cells in of the lactating cows and release these enzymes in circulation. Additionally, tBIL. concentrations positively correlated with the NEFA and BHB concentrations and serum activites of AST, GGT and ALT in this study. These results are in the accordance with previously studies $[1,4,7,9,15,16]$ and suggested that the process of lipomobilization was enough to cause liver lesions in the early and full lactating cows. This statement confirmed a significant negative correlation between blood NEFA and BHB with blood TG in current study.
This study has shown a possibility of the development a fat infiltration of the liver in lactation cows which was confirmed by a significant correlation between biochemical markers.

\section{CONCLUSION}

These results demonstrate that mild fatty liver physiologically occurred during postpartum period inducing some cellular lesions and a weak function impairment of the liver. On the basis of changes and relationships of blood biochemical markers, this study suggests that early lactation cows showed physiological adaptive changes, which were associated with subclinical ketosis and mild fat infiltration of liver cells.

\section{MANUFACTURERS \\ ${ }^{1}$ Oxus Lab. Kragujevac, Serbia. \\ ${ }^{2}$ Fortress Diagnostics. Antrim, UK. \\ ${ }^{3}$ Randox Clinical Diagnostics. Crumlin, UK.}

Funding. This research was supported by grants no. TR 31001 from Ministry of education Serbia, science and technological development.

Declaration of interest. The authors report no conflicts of interest. The authors alone are responsible for the content and writing of paper.

\section{REFERENCES}

1 Bobe G., Young J.W. \& Beitz D.C. 2004. Pathology, etiology, prevention, treatment of fatty liver in dairy cows. Journal of Dairy Science. 87: 3105-3124.

2 Brunner N., Groeger S., Raposo J.C., Bruckmaier R.M. \& Gross J.J. 2019. Prevalence of subclinical ketosis and production diseases in dairy cows in Central and South America, Africa, Asia, Australia, New Zealand, and Eastern Europe. Translational Animal Science. 3: 19-27.

3 Civelek T., Aydi I., Cingi, C.C., Yilmaz O. \& Kabu M. 2011. Serum non-esterified fatty acids and beta-hydroxybutyrate in dairy cows with retained placenta. Pakistan Veterinary Journal. 31: 341-344.

4 Dann H.M., Morin D.E., Murphy M.R., Bollerog A. \& Drackely J.K. 2005. Prepartum intake, postpartum induction of ketosis, and periparturient disorders affect the metabolic status of dairy cows. Journal of Dairy Science. 88: 3249-3264.

5 Djoković R., Ilić Z., Kurćubić V., Petrović M. \& Dosković V. 2011. Functional and morphological state of the liver in Simmental dairy cows during transitional period. Revue de Médecine Vétérinaire. 162: 574-579.

6 Djokovic R., Cincovic M., Belic B., Toholj B., Davidov I. \& Hristovska T. 2015. Relationship between blood metabolic hormones, metabolites and energy balance in Simmental dairy cows during peripartum period and lactation. Pakistan Veterinary Journal. 35: 163-167.

7 Drackle J.K., Dann H.M., Douglas G.N., Janovick-Gurtzky N.A., Lutherland N.B., Underwood J.P. \& Loor J.J. 2005. Physiological and pathological adaptations in dairy cows that may increase susceptibility to periparturient diseases and disorders. Italian Journal of Animal Science. 4: 323-344.

8 Duffield T. 2000. Subclinical ketosis in lactating dairy cattle. Veterinary Clinics of North America: Food Animal Practice. 16: 231-253.

9 Gonzales F.D., Muino R., Pereira V. \& Campos R. 2011. Relationship among blood indicators of lipomobilization and hepatic function during early lactation in high-yielding dairy cows. Journal of Veterinary Science. 12: 251-255. 
10 Gros J., Van Dorland H.A., Bruckmaiker R.M. \& Schwar F.J. 2011. Performance and metabolic profile of dairy cows during a lactation and deliberately induced negative energy balance with subsequent realimentation. Journal of Dairy Science. 94: 1820-1830.

11 Herdt T.H., Leisman J.S., Gerlof B.J. \& Emery R.S. 1983. Reduction of serum triacilglycerol-rich lipoprotein concentrations in cows with hepatic lipidosis. American Journal of Veterinary Research. 44: 293-296.

12 Jorritsma R.H., Jorritsma Y.H., Schukken P.C., Bartlett T., Wensing T. \& Wenting G. 2001. Prevalence and indicators of postpartum fatty infiltration of the liver in nine commercial dairy herds in the Netherlands. Livestock Production Science. 68: 53-60.

13 Jozwik A., Strzakowska N., Bagnicka E., Grzybek W., Krzyżewski J., Poławska E., Kolataj A. \& Horbańczuk J.O. 2012. Relationship between milk yield, stage of lactation, and some blood serum metabolic parameters of dairy cows. Czech Journal of Animal Science. 57: 353-360.

14 Lubojacka V., Pechova A., Dvorak R., Drastich P., Kummer V. \& Poul J. 2005. Liver steatosis following supplementation with fat in dairy cows diets. Acta Veterinaria Brno 74: 217-224.

15 Oetzel G.R. 2004. Monitoring and testing dairy herds for metabolic disease. Veterinary Clinics of North America: Food Animal Practice. 20: 651-674.

16 Overton T.R. \& Waldron M.R. 2004. Nutritional management of transition dairy cows: Strategies to optimize metabolic health. Journal of Dairy Science. 87: E105-E119.

17 Pechova A., Llek J. \& Halouzka R. 1997. Diagnosis and control of the development of hepatic lipidosis in dairy cows in the peri-parturient period. Acta Veterinaria Brno. 66: 235-243.

18 Radostits O.M., Blood D.C., Gay C.C. \& Hinchcliff K.W. 2000. Veterinary Medicine - A Textbook of the Diseases of Cattle, Sheep, Pigs, Goats and Horses. 9th edn. London: W.B. Saunders Co., 935p.

19 Sevinc M., Basoglu A., Guzulbekta H. 2003. Lipid and lipoprotein levels in dairy cows with fatty liver. Turkish Journal of Veterinary and Animal Science. 27: 295-299.

20 Stojevic Z., Pirsljin J., Milinkovic-Tur S., Zdwlar-Tuk M. \& Ljubic B.B. 2005. Activities of AST, ALT and GGT in clinically healthy dairy cows during lactation and in the dry period. Veterinarski Arhiv. 75: 67-73.

21 Veenhuizen J.J., Drackley J.K., Richard M.J., Sanderson T.P., Miller L.D. \& Joung J.W. 1991. Metabolic changes in blood and liver during development and early treatment of experimental fatty liver and ketosis in cows. Journal of Dairy Science. 74: 4238-4253.

22 West H.J. 1990. Effect on liver function of acetonaemia and the fat cow syndrome in cattle. Research of Veterinary Science. 48: 221-227. 